\title{
La normativa legal como pilar de gestión en la economía social y solidaria del Ecuador
}

\section{The legal regulation as a pillar of management in the social and solidarity economy of Ecuador}

\author{
Roberto Fabián Sánchez Chávez. ${ }^{1}$, Renato Daniel Basantes Silva. ${ }^{2}$, Norma Yolanda \\ Villacís Venegas. ${ }^{3}$, Marco Vinicio Moyano Cascante. ${ }^{4}$, \& Norma del Rocío Toledo Castillo. ${ }^{5}$
}

\begin{abstract}
.
DOI: https://doi.org/10.33262/cienciadigital.v3i2.6.561

The purpose of this investigation was to determine the application of legal regulations in the Savings and Credit Cooperatives Segment 1 of Ecuador, with emphasis on the technical assets constituted and solvency. The development of this study has a descriptive scope, that is, they only intend to measure or collect information independently or jointly on the concepts or variables to which they refer, different methods such as the theoretical one were used, as well as the analytical method Synthetic for the review of the literature and the logical historical itself that is necessary to address the issue of legal regulations as a pillar of management in the social and solidarity economy of Ecuador. It was demonstrated with the results obtained that the cooperatives legally comply with the requirements established in article 190 of the Monetary and Financial Organic Code, which through results and values can be corroborated that the aforementioned institutions, due to their high value in assets, have

\footnotetext{
${ }^{1}$ Escuela Superior Politécnica de Chimborazo, Facultad de Administración de Empresas, Riobamba, Ecuador, roberto.sanchez@espoch.edu.ec

${ }^{2}$ Escuela Superior Politécnica de Chimborazo, Facultad de Administración de Empresas, Riobamba, Ecuador, renatoderecho@hotmail.com

${ }^{3}$ Escuela Superior Politécnica de Chimborazo, Facultad de Administración de Empresas, Riobamba, Ecuador, norma.villacis@espoch.edu.ec

${ }^{4}$ Escuela Superior Politécnica de Chimborazo, Facultad de Administración de Empresas, Riobamba, Ecuador, marvinmoycas@gmail.com

${ }^{5}$ Escuela Superior Politécnica de Chimborazo, Facultad de Administración de Empresas, Riobamba, Ecuador, norma.toledo@espoch.edu.ec
} 
an indicator of very high solvency which indicates that the management is not favorable.

Keywords: Economy, normative, social, solidary, legal.

\section{Resumen.}

El desarrollo de esta investigación tuvo como objetivo determinar la aplicación de la normativa legal, en las Cooperativas de Ahorro y Crédito Segmento 1 del Ecuador, con énfasis en el patrimonio técnico constituido y la solvencia. El desarrollo de este estudio tiene un alcance descriptivo, es decir, únicamente pretenden medir o recoger información de manera independiente o conjunta sobre los conceptos o las variables a las que se refieren, se usó diferentes métodos como el teórico, al igual que el método analítico- sintético para la revisión de la literatura y el histórico lógico mismo que es necesario para abordar el tema de la normativa legal como pilar de gestión en la economía social y solidaria del Ecuador. Se demostró con los resultados obtenidos que las cooperativas cumplen legalmente con los requerimientos establecidos en el artículo 190 del Código Orgánico Monetario y financiero lo que mediante resultados y valores se puede corroborar que las instituciones mencionadas, por su valor elevado en activos, tienen un indicador de solvencia muy elevada lo que indica que la gestión que no es favorable.

Palabras claves: Economía, normativa, social, solidaria, legal.

\section{Introducción.}

La Constitución de la República del Ecuador, en su artículo 283 define al sistema económico como social y solidario y reconoce diversas formas de organización económica: pública, privada, mixta, y popular y solidaria, bajo este lineamiento descrito en la Carta Magna del país se considera la planificación nacional para el "Buen Vivir" y denominado por el gobierno actual como "Plan Toda una Vida", gracias a esta condición se establece el alcance del sistema económico y se lo fija como objetivo nacional.

Adicionalmente, la publicación de la Ley Orgánica de Economía Popular y Solidaria (LOEPS) -en 2011- representó un escalón hacia el reconocimiento y fortalecimiento del sector, ya que, a partir de este instrumento, se generó una nueva institucionalidad orientada al fomento y promoción; estabilidad, solidez y correcto funcionamiento de los actores que conforman el sector. Es así que, la creación de la Superintendencia de Economía Popular y Solidaria (SEPS) - en junio de 2012- constituye un avance en la construcción de una arquitectura institucional pública alineada a la rectoría, regulación, control y supervisión del sector económico popular y solidario. 
El artículo. 309 de la Constitución de la República señala que el sistema financiero nacional se compone de los sectores público, privado y del popular y solidario;

El artículo 311 de la misma Constitución señala que el sector financiero popular y solidario se compondrá de cooperativas de ahorro y crédito, entidades asociativas o solidarias, cajas y bancos comunales, cajas de ahorro y que las iniciativas de servicios del sector financiero popular y solidaria y de las micro, pequeñas y medianas unidades productivas, recibirán un tratamiento diferenciado y preferencial del Estado, en la medida en que impulsen el desarrollo de la economía popular y solidaria;

El artículo 319 de la Constitución de la República establece que se reconocen diversas formas de organización de la producción en la economía, entre otras las comunitarias, cooperativas, empresas públicas o privadas, asociativas, familiares, domésticas, autónomas y mixtas;

Según lo establecido en la constitución del Ecuador, es fundamental regir un proceso de cumplimiento, control y seguimiento de la normativa legal creada para los sectores que integran la economía social del país. La normativa vigente es especial y según la característica del sector fundamenta sus artículos y cuerpos legales específicos.

\section{Desarrollo}

La economía social y solidaria (ESS) es el conjunto de emprendimientos asociativos de producción, transformación, comercialización y servicios de grupos de personas que se han juntado con el fin de mejorar su calidad de vida y el de su comunidad, generando desarrollo territorial y fortalecimiento de tejidos de los colectivos sociales (Arcos et al, 2011: 9).

En el Ecuador se ha constituido como bandera en los actores, convirtiendo la ESS en innovación social ligadas a las variables territoriales y a las dinámicas de los sectores. Se puede decir que ésta economía tiene su origen en el siglo XIX, puesto que es aquí donde toman fuerza las organizaciones de forma cooperativa, asociativa y de ahorro y crédito, las cuales surgen como respuesta a las necesidades de una parte de la población (Guridi et al, 2014: 15).

En los años sesenta y setenta la economía solidaria presenta una importante expansión, tanto en Europa como en América Latina, debido a la crisis económica por la que atravesaba el mundo. Sin embargo, se menciona que ésta economía ya existía desde años remotos en donde los agricultores se asociaban y se ayudaban mutuamente para obtener productos y alimentos que satisfagan sus necesidades. 
De conformidad con el artículo 261 numeral 5 de la Constitución de la República, el Estado central tendrá competencias exclusivas sobre las políticas económica y monetaria, entre otras;

El artículo 283 de la Carta Suprema del Estado establece que el sistema económico es social y solidario; reconoce al ser humano como sujeto y fin; propende a una relación dinámica y equilibrada entre sociedad, Estado y Mercado, en armonía con la naturaleza; tiene como objetivo garantizar la producción y reproducción de las condiciones materiales e inmateriales que posibiliten el Buen Vivir; y prescribe que el sistema económico se integra por las formas de organización económica, pública, privada, mixta, popular y solidaria, y las demás que la Constitución determine;

El artículo 284 de la Constitución de la República dispone que la política económica tendrá los siguientes objetivos:

1) Asegurar una adecuada distribución del ingreso y de la riqueza nacional;

2) Incentivar la producción nacional, la productividad y competitividad sistémicas, la acumulación del conocimiento científico y tecnológico, la inserción estratégica en la economía mundial y las actividades productivas complementarias en la integración regional;

3) Asegurar la soberanía alimentaria y energética;

4) Promocionar la incorporación del valor agregado con máxima eficiencia, dentro de los límites biofísicos de la naturaleza y el respeto a la vida y a las culturas;

5) Lograr un desarrollo equilibrado del territorio nacional, la integración entre regiones, en el campo, entre el campo y la ciudad, en lo económico, social y cultural;

6) Impulsar el pleno empleo y valorar todas las formas de trabajo con respeto a los derechos laborales;

7) Mantener la estabilidad económica, entendida como el máximo nivel de producción y empleo sostenibles en el tiempo;

8) Propiciar el intercambio justo y complementario de bienes y servicios en mercados transparentes y eficientes;

9) Impulsar un consumo social y ambientalmente responsable;

De acuerdo con el artículo 302 numerales 2 y 3 de la Constitución de la República, la política monetaria, crediticia, cambiaria y financiera tendrán como objetivos: establecer niveles de liquidez global que garanticen adecuados márgenes de seguridad financiera y orientar los excedentes de liquidez hacia la inversión requerida para el desarrollo del país, respectivamente;

El artículo 303 de la Carta Política del Estado prescribe que la formulación de las políticas monetaria, crediticia, cambiaria y financiera es facultad exclusiva de la Función Ejecutiva 
que se instrumentará a través del Banco Central y que la ejecución de la política crediticia y financiera también se ejercerá a través de la banca pública;

El artículo 308 de la Constitución de la República ordena que las actividades financieras son un servicio de orden público y podrán ejercerse previa autorización del Estado, de acuerdo con la ley;

Que, el artículo 309 de la Constitución de la República dispone que el sistema financiero nacional se compone de los sectores público, privado y del popular y solidario, que intermedian recursos del público y prescribe que cada uno de estos sectores contará con normas y entidades de control específicas y diferenciadas, que se encargarán de preservar su seguridad, estabilidad, transparencia y solidez;

Siendo necesario sistematizar dentro de un cuerpo legal todas las disposiciones de leyes relacionadas con las políticas monetaria, financiera, crediticia y cambiaria, como parte de la nueva arquitectura financiera ecuatoriana; determinando las instituciones responsables de la formulación de las políticas en los ámbitos monetario, financiero, crediticio y cambiario, así como de la regulación de los servicios financieros de orden público y de su control; y,

Adicionalmente dentro del control a las organizaciones del sector real de la economía, el inciso segundo, del artículo 144 de la Ley ibídem, en concordancia con el primer inciso del artículo 149 de su reglamento general, determinan que la regulación de la Economía Popular y Solidaria es potestad de la Función Ejecutiva y la ejercerá a través del Ministerio Coordinador de Desarrollo Social; concordante con el numeral 4, del artículo 150 del Reglamento General de la Ley ibídem atribuye al Ministerio Coordinador de Desarrollo Social la facultad de regular los procedimientos para la constitución, funcionamiento y control de las organizaciones de la Economía Popular y Solidaria, en los aspectos no previstos en la Ley y su Reglamento.

Según lo establecido en los cuerpos legales citados, se procedió a realizar el análisis por sector y por tipo de norma legal el nivel de cumplimiento que las organizaciones efectúan.

En el análisis efectuado se establece el marco de políticas, regulaciones, supervisión, control y rendición de cuentas que rige los sectores financieros y no financiero, así como los regímenes de valores, aportes y actividades, en el ejercicio de sus actividades y la relación con sus usuarios.

El sector real o también conocido como el No Financiero se caracteriza por una pluralidad de actores que, de acuerdo con el marco normativo institucional actual, conforman los sectores cooperativo, asociativo y comunitario, clasificándose en: a) cooperativas de producción; b) cooperativas de consumo; c) cooperativas de vivienda; d) cooperativas de 
servicios; e) asociaciones productivas; y, f) organizaciones comunitarias. Estas organizaciones realizan sus actividades basadas, a priori, en relaciones de solidaridad, cooperación y reciprocidad, y ubican al ser humano como sujeto y fin de toda actividad económica por sobre el lucro, la competencia y la acumulación de capital.

El Sector Financiero Popular y Solidario está conformado por: a) cooperativas de ahorro y crédito; b) cajas solidarias y de ahorro; c) cajas centrales; y d) bancos comunales. Estas organizaciones se identifican, en principio, por su lógica asociativa y realizan actividades de intermediación financiera y de responsabilidad social con sus socios, generando finanzas al servicio de las necesidades de las personas.

\section{Dos frentes de registro y supervisión del sector cooperativo}

La Ley Orgánica de la Economía Popular y Solidaria, en el artículo 21 establece que el sector cooperativo, "Es el conjunto de cooperativas entendidas como sociedades de personas que se han unido en forma voluntaria para satisfacer sus necesidades económicas, sociales y culturales en común, mediante una empresa de propiedad conjunta y de gestión democrática, con personalidad jurídica de derecho privado e interés social. (...)”;

La Ley ibídem, en el artículo 23 señala que "Las cooperativas, según la actividad principal que vayan a desarrollar, pertenecerán a uno solo de los siguientes grupos: producción, consumo, vivienda, ahorro y crédito y servicios. En cada uno de estos grupos se podrán organizar diferentes clases de cooperativas, de conformidad con la clasificación y disposiciones que se establezcan en el Reglamento de esta Ley"

Tabla.1 Clasificación del Sector No Financiero

\begin{tabular}{|c|c|c|c|c|}
\hline \multirow[t]{2}{*}{ Nivel } & \multicolumn{2}{|r|}{ Producción } & \multicolumn{2}{|c|}{ Transporte } \\
\hline & Activos (USD) & Número de socios & Activos (USD) & Número de socios \\
\hline Nivel 1 & $0-200.000,00$ & hasta 80 & $0-800.000,00$ & hasta 100 \\
\hline \multirow[t]{2}{*}{ Nivel 2} & 200.000,01 o más & Sin importar el número de socios & 800.000,01 o más & $\begin{array}{l}\text { Sin importar el } \\
\text { número de socios }\end{array}$ \\
\hline & $\begin{array}{l}\text { Sin importar el } \\
\text { monto de activos }\end{array}$ & más de 80 & $\begin{array}{c}\text { Sin importar el monto } \\
\text { de activos }\end{array}$ & más de 100 \\
\hline \multirow[t]{2}{*}{ Nivel } & \multicolumn{2}{|r|}{ Vivienda } & \multicolumn{2}{|c|}{ Servicios y Consumo } \\
\hline & Activos (USD) & Número de socios & Activos (USD) & Número de socios \\
\hline Nivel 1 & $0-1.600 .000,00$ & hasta 1000 & $0-100.000,00$ & hasta 50 \\
\hline Nivel 2 & 1.600.000,01 o más & Sin importar el número de socios & 100.000,01 o más & $\begin{array}{l}\text { Sin importar el } \\
\text { número de socios }\end{array}$ \\
\hline
\end{tabular}




\begin{tabular}{|c|c|c|c|c|}
\hline & $\begin{array}{c}\text { Sin importar el } \\
\text { monto de activos }\end{array}$ & más de 1000 & $\begin{array}{c}\text { Sin importar el monto } \\
\text { de activos }\end{array}$ & más de 50 \\
\hline
\end{tabular}

Fuente: SEPS

Elaboración: Los Autores

Según la "Norma para la segmentación de las entidades del sector financiero popular y solidario", manifiesta lo siguiente:

Artículo 1.- Las entidades del sector financiero popular y solidario de acuerdo al tipo y al saldo de sus activos se ubicarán en los siguientes segmentos:

Tabla.2 Clasificación según los Activos Sector Financiero

\begin{tabular}{cl}
\hline Segmento & Activos (USD) \\
\hline 1 & Mayor a 80'000.000,00 \\
2 & Mayor a 20'000.000,00 hasta 80'000.000,00 \\
3 & Mayor a 5'000.000,00 hasta 20'000.000,00 \\
4 & Mayor a 1'000.000,00 hasta 5'000.000,00 \\
5 & Hasta 1'000.000,00 \\
& Cajas de Ahorro, bancos comunales y cajas comunales \\
\hline
\end{tabular}

Fuente: SEPS

Elaboración: Los Autores

Artículo 2.- Las entidades de los segmentos 3, 4 y 5 definidas en el artículo anterior se segmentarán adicionalmente al vínculo con sus territorios. Se entenderá que las entidades referidas tienen vínculo territorial cuando coloquen al menos el 50\% de los recursos en los territorios donde estos fueron captados.".

En el artículo 447 del Código Orgánico Monetario y Financiero se indica que las cooperativas se ubicarán en los segmentos que la Junta determine.

La Superintendencia de Economía Popular y Solidaria se acoge a lo dispuesto por el Código Monetario Financiero y precautelando los intereses del Sector de la Economía Popular y Solidaria.

A raíz de la creación del ente regulador los controles efectuados a las cooperativas fueron muy estrictos provocando una serie de fusiones y liquidaciones en ellas. Es importante señalar que en el boletín emitido por la Superintendencia de Economía Popular y Solidaria para agosto del año 2018 reconoce que existen 633 cooperativas de ahorro y crédito 
distribuidas en los cinco segmentos. (Superintendencia de Economía Popular y Solidaria, 2018).

Tabla.3 Distribución de cooperativas por segmentos

\begin{tabular}{cc}
\hline Segmento & $\mathbf{N}^{\mathbf{0}}$ de entidades \\
\hline 1 & 31 \\
2 & 40 \\
3 & 82 \\
4 & 182 \\
5 & 298 \\
Total & 633 \\
\hline
\end{tabular}

Fuente: SEPS

Elaboración: Los Autores

Basada en la norma legal que aplican en las organizaciones de los sectores Financiero y No Financiero bajo el control de la SEPS, se procede hacer un análisis del riesgo legal y de cumplimiento a las disipaciones, resoluciones, artículos determinadas en los diferentes cuerpos legales que se aplican en las cooperativas de ahorro y crédito que integran el sector financiero.

Dentro del registro de organizaciones de la Superintendencia de Economía Popular y Solidaria, se efectúa un análisis técnico legal sobre el cumplimiento de la normativa que permite la segmentación de las organizaciones integrantes del segmento 1 del sector financiero, determinando el cumplimiento y permitiendo establecer un ranking de las principales cooperativas de ahorro y crédito pertenecientes al segmento 1 con un alto valor en sus activos.

Tabla.4 Ranking de Cooperativas del segmento 1

\begin{tabular}{lcr}
\hline \multicolumn{1}{c}{ Institución } & Ranking & \multicolumn{1}{c}{ Activos $\mathbf{( \$ )}$} \\
\hline Juventud Ecuatoriana y Progresista Ltda. & 1 & $\$ 1.879 .546 .970,38$ \\
Jardín Azuayo Ltda. & 2 & $\$ 848.519 .466$ \\
Policía Nacional Ltda. & 3 & $\$ 766.287 .436$ \\
Cooprogreso Ltda. & 4 & $\$ 499.232 .211$ \\
29 de Octubre Ltda. & 5 & $\$ 486.821 .550$ \\
Oscus Ltda. & 6 & $\$ 367.448 .339$ \\
San Francisco Ltda. & 7 & $\$ 325.131 .995$ \\
De la Pequeña Empresa de Cotopaxi Ltda. & 8 & $\$ 304.232 .894$ \\
Riobamba Ltda. & 9 & $\$ 300.417 .977$ \\
Alianza del Valle Ltda. & 10 & $\$ 297.319 .856$ \\
\hline
\end{tabular}

Fuente: SEPS

Elaboración: Los Autores 
El Título II del Código Orgánico Monetario y Financiero (2014) menciona al Sistema Financiero Nacional en el cual dentro del artículo 190 se referencia a la solvencia y patrimonio técnico haciendo énfasis en que toda entidad perteneciente al sistema financiero ecuatoriano debe contar con valor suficiente en su patrimonio para poder proteger las operaciones que se ejecutan en la entidad, poder cancelar deudas y afirmar el desempeño macroeconómico de la institución. (Código Orgánico Monetario y Financiero, 2014).

Es decir que la solvencia dentro de las instituciones financieras juega un papel primordial pues a través de esta se puede realizar las cancelaciones de diferentes obligaciones que presenten las entidades financieras ya sean a corto o a largo plazo, sin que el patrimonio que constituye a cada institución se vea afectado de alguna manera.

Para calcular el indicador de solvencia es necesario tener en consideración los valores de dos cuentas; Patrimonio técnico constituido y activos y contingentes ponderados por riesgo para posteriormente efectuar con estos valores la operación pertinente.

\section{Solvencia $=$ Patrimonio técnico constituido / Activos y contingentes por riesgo}

Según la Resolución No 131-2015-F emitida por la Junta de Regulación Monetaria y Financiera en su artículo 2 hace énfasis en el patrimonio técnico constituido considerándolo como el valor que toda entidad financiera debe tener disponible para resguardar sus operaciones y cubrir pérdidas de improviso. La composición de este patrimonio es la sumatoria del patrimonio primario y secundario. Dentro de la resolución el artículo $\mathrm{N}^{\circ} 3$ hace referencia en que toda entidad perteneciente al segmento 1 debe mantener una relación del patrimonio constituido y la suma ponderada por riesgo de activos y contingentes de al menos el 9\%. (Junta de Política Monetaria y Financiera, 2015).

Así mismo dentro del Artículo 190 del Código Orgánico Monetario y Financiero (2014) se enfatiza que las entidades pertenecientes a los sectores financieros tanto público, privados como el popular y solidario pertenecientes al segmento 1 deben de poseer una relación entre el patrimonio técnico y los activos totales y contingentes, el cual no podría ser inferior al $4 \%$. (Código Orgánico Monetario y Financiero, 2014)

El Código Orgánico Monetario y Financiero en el artículo 191 establece la conformación del patrimonio técnico siendo esta la sumatoria de cuentas pertenecientes al patrimonio como su capital, reservas, en el caso de que exista utilidad o excedente del ejercicio, obligaciones, utilidades, aporte de futuras capitalizaciones y obligaciones convertibles; a estas cuentas se les deduce amortizaciones, depreciaciones y deficiencia de provisiones. (Código Orgánico Monetario y Financiero, 2014). 
Los porcentajes de ponderaciones de los activos y contingentes están divididos en seis grupos los cuales están clasificados de acuerdo con su naturaleza y se encuentran estipulados dentro de la norma general de instituciones financieras vigente del Ecuador (Junta de Política Monetaria y Financiera, 2015).

Los factores de ponderación son los siguientes:

- Activos y contingentes ponderados con el $0 \%$

- Activos y contingentes ponderados con el $20 \%$

- Activos y contingentes ponderados con el 50\%

- Activos y contingentes ponderados con el $100 \%$

\section{Metodología}

El desarrollo de la presente investigación tiene un alcance descriptivo, es decir, únicamente pretenden medir o recoger información de manera independiente o conjunta sobre los conceptos o las variables a las que se refieren, se usó diferentes métodos como el teórico, al igual que el método analítico- sintético para la revisión de la literatura y el histórico lógico mismo que es necesario para abordar el tema de la normativa legal como pilar de gestión en la economía social y solidaria del Ecuador, en lo que tiene que ver a sus aspectos teóricos necesarios para el desarrollo de la presente investigación. Esta investigación plantea una discusión conceptual de la normativa enmarcada en los instrumentos jurídicos vigentes, es importante destacar el carácter dinámico del sector económico popular y solidario, que procura otra forma de hacer economía.

Se utilizó la investigación documental, con el objeto de determinar la aplicación en el Ecuador, de la normativa legal, en las cooperativas de ahorro y crédito segmento uno, haciendo énfasis en el patrimonio técnico constituido considerándolo como el valor que toda entidad financiera debe tener disponible para resguardar sus operaciones y cubrir pérdidas de improviso, de al menos el 9\%. Se desarrolló esta investigación, para conocer la realidad, del sistema financiero popular y solidario Segmento 1, y conocer la situación actual.

La Población en la presente investigación corresponde a las 16 cooperativas de ahorro y crédito que conforman el Segmento 1, analizando los estados financieros de las mencionadas cooperativas para determinar su patrimonio técnico. 


\section{Resultados}

Analizando la aplicación de la normativa legal y haciendo énfasis en el patrimonio técnico constituido, se determina los siguientes resultados:

Tabla 5. Estudio legal sobre la aplicación de la normativa vigente sobre Patrimonio técnico segmento 1

\begin{tabular}{|c|c|c|c|c|c|c|c|}
\hline & & $\mathbf{A}$ & $\mathbf{B}$ & $\mathbf{C}$ & D & $\mathbf{E}$ & $\mathbf{F}$ \\
\hline No. & RAZÓN SOCIAL & $\begin{array}{l}\text { Total patrimonio } \\
\text { técnico primario }\end{array}$ & $\begin{array}{c}\text { Total patrimonio } \\
\text { técnico secundario }\end{array}$ & $\begin{array}{c}(\mathbf{a}+\mathbf{b}) \text { patrimonio } \\
\text { técnico constituido } \\
(\mathrm{ptc})\end{array}$ & $\begin{array}{c}\text { Total activos } \\
\text { ponderados por } \\
\text { riesgo (appr) }\end{array}$ & Solvencia & $\begin{array}{c}\text { Patrimonio técnico } \\
\text { requerido } \\
\text { (ptr) } 9 \%\end{array}$ \\
\hline 1 & Juventud Ecuatoriana Progresista Ltda. & 179.693 .983 & - & 179.693 .983 & 1.622 .067 .887 & $11,08 \%$ & 145.986 .110 \\
\hline 2 & Jardín Azuayo Ltda. & 114.684 .616 & 47.743 & 114.732 .359 & 716.559 .947 & $16,01 \%$ & 64.490 .395 \\
\hline 3 & Policía Nacional Ltda. & 133.227 .244 & 584.553 & 133.811 .797 & 656.302 .951 & $20,39 \%$ & 59.067 .266 \\
\hline 4 & 29 de Octubre Ltda. & 61.808 .284 & 19.800 & 61.828 .084 & 392.345 .579 & $15,76 \%$ & 35.311 .102 \\
\hline 5 & Cooprogreso Ltda. & 49.636 .217 & 577.877 & 50.214 .095 & 378.798 .310 & $13,26 \%$ & 34.091 .848 \\
\hline 6 & Oscus Ltda. & 44.160 .680 & 552.252 & 44.712 .932 & 262.870 .182 & $17,01 \%$ & 23.658 .316 \\
\hline 7 & Alianza Del Valle Ltda. & 41.204 .775 & 136.639 & 41.341 .414 & 250.885 .025 & $16,48 \%$ & 22.579 .652 \\
\hline 8 & San Francisco Ltda. & 56.320 .572 & 412.440 & 56.733 .012 & 238.520 .703 & $23,79 \%$ & 21.466 .863 \\
\hline 9 & La Pequeña Empresa de Cotopaxi Ltda. & 56.605 .360 & 205.982 & 56.811 .342 & 233.587 .285 & $24,32 \%$ & 21.022 .856 \\
\hline 10 & Riobamba Ltda. & 49.312 .633 & 427.812 & 49.740 .444 & 228.106 .533 & $21,81 \%$ & 20.529 .588 \\
\hline 11 & Vicentina Manuel Esteban Godoy Ortega Ltda. & 44.803 .700 & 815.165 & 45.618 .864 & 214.218 .221 & $21,30 \%$ & 19.279 .640 \\
\hline 12 & Andalucía Ltda. & 33.446 .138 & 365.871 & 33.812 .009 & 212.386 .720 & $15,92 \%$ & 19.114 .805 \\
\hline 13 & La Pequeña Empresa Biblián Ltda. & 33.622 .306 & 33.794 & 33.656 .100 & 181.127 .012 & $18,58 \%$ & 16.301 .431 \\
\hline 14 & Mushuc Runa Ltda. & 41.609 .235 & - & 41.609 .235 & 180.905 .601 & $23,00 \%$ & 16.281 .504 \\
\hline 15 & Tulcán Ltda. & 25.867 .504 & 77.902 & 26.445 .406 & 151.020 .266 & $17,51 \%$ & 13.591 .824 \\
\hline 16 & Pablo Muñoz Vega Ltda. & 22.851 .195 & 259.785 & 23.110 .980 & 143.581 .875 & $16,10 \%$ & 12.922 .369 \\
\hline
\end{tabular}

Fuente: SEPS

Elaboración: Los Autores 


\section{Conclusiones.}

Mediante la ejemplificación y ejecución de lo planteado en el Código Orgánico Monetario y Financiero, Ley de Economía Popular y Solidaria, Resoluciones de la Superintendencia de Economía Popular y Solidaria, Resoluciones de la Junta de Regulación Monetaria y otras disposiciones legales se puede determinar las siguientes conclusiones:

- Las Cooperativas de Ahorro y Crédito Segmento 1, poseen un patrimonio técnico constituido conforme la normativa legal vigente en el Ecuador.

- Al ejecutar un análisis del balance general y el estado de pérdidas y ganancias de la institución podemos darnos cuenta de que son entidades que poseen solvencia patrimonial; en comparación con las cooperativas de otros segmentos.

- Se pudo reflejar que cumple legalmente con los requerimientos establecidos en el artículo 190 del Código Monetario y financiero lo que mediante los resultados y valores se puede corroborar que las instituciones mencionadas a pesar de ser cooperativas reconocidas a nivel nacional e internacional; por su valor elevado en activos, su solvencia no es favorable, debido a que sus activos contingentes ponderados por riesgo poseen un valor alto.

\section{Referencias bibliográficas.}

Coca, J. (2015). Impacto de Basileaen la confianza de los ecuatorianos para un nuevo sistema financiero. Observatorio Economía Latinoamericana, 1-8. Obtenido de http://www.eumed.net/cursecon/ecolat/ec/2015/basilea.html

Código Orgánico Monetario y Financiero. (2014). Código Orgánico Monetario y Financiero. Quito: Corporación de Estudios y Publicaciones.

Congreso Nacional. (20 de Mayo de 2014). Ley Orgánica de Instituciones del Sistema Financiero. Obtenido de Ley Orgánica de Instituciones del Sistema Financiero: http://diccionario.administracionpublica.gob.ec/adjuntos/ley-o-de-institucionesdelsistema-financiero.pdf

Constitución de la República del Ecuador, Concordancias. (2008). Constitución de la República del Ecuador, Concordancias. Quito: Corporación de Estudios y Publicaciones. O+DIC+2018.pdf/e18e5d42-9d7d-4748-8463-4c8d55f5e4f1

Jácome, H., y Ruíz, M. (Octubre de 2013). ResearchGate. Obtenido de https://www.researchgate.net/publication/316846961_El_sector_economico_pop ular_y_solidario_en_Ecuador_Diagnostico_y_modelo_de_supervision

Jara, C., y Umpierrez, S. (2014). Evolución del Sector Público Ecuatoriano desde 1998 a 
2013. Revista Enfoques: Ciencia Política y Administración Pública, XXI(21), 131-

137. Obtenido de https://www.redalyc.org/pdf/960/96032813007.pdf

Junta de Política Monetaria y Financiera. (2015). Obtenido de http://www.seps.gob.ec/documents/20181/25522/Resol131.pdf/3e109e8097484852-a7a3-42801 aeab09d

Junta de Política Monetaria y Financiera. (2015). Obtenido de Ministerio de Finanzas: https://www.juntamonetariafinanciera.gob.ec/PDF/Resolucion\%20No.\%200382015 -F.pdf?dl=0

Morillo , L., y Puetate, J. (2017). Evaluación económica, financiera y social para la apertura de Agencias de Cooperativas de Ahorro y Crédito. Revista Publicando, 4(10), 70-78. Obtenido de https://www.rmlconsultores.com/revista/index.php/crv/article/viewFile/477/pdf_ 303

Saltos, J., Mayorga, M., y Ruso, F. (2016). La economía popular y solidaria: un estudio exploratorio del sistema en Ecuador con enfoque de control y fiscalización. Cofín Habana, $\quad$ 10(2), 55-75. Obtenido de http://scielo.sld.cu/scielo.php?script=sci_arttext\&pid=S2073$60612016000200003 \# f 1$

Shapovalov, M. A. (Junio de 2015). Derecho financiero internacional: historia, estado actual y perspectiva de desarrollo. Dikaion, 24(1), 171-195. doi:10.5294/dika.2015.24.1.8

Superintendencia de Bancos. (16 de Marzo de 2017). Superintendencia de Bancos. $\begin{array}{lllll}\text { Recuperado el de } 20 \text { Enero de } & \end{array}$ https://www.superbancos.gob.ec/bancos/glosario-de-terminos/

Tenesaca , K., Villanueva , J., Malo, Z., y Higuerey, Á. (2017). Sistema bancario de Ecuador: una aproximación a sus indicadores de estabilidad y eficiencia.

Publicando, 4(13), 255-273. Obtenido de https://www.rmlconsultores.com/revista/index.php/crv/article/view/789/pdf_573

Torres, N., Fierro, P. E., y Alonso, A. (2017). Balance de la economía popular y solidaria en Ecuador. Economía y Desarrollo, 158(1), 180-196. Obtenido de https://www.redalyc.org/pdf/4255/425553381014.pdf

Viñan, D., Lombeida, B., Orozco, A., y Herman, E. (2016). Análisis de la Coyuntura del Sector Financiero y Solidario. Quito. Obtenido de http://www.seps.gob.ec/documents/20181/26626/COYUNTURA\%20SFPS\%20 2015.pdf 


\section{PARA CITAR EL ARTÍCULO INDEXADO.}

Sánchez Chávez, R. F., Basantes Silva, R., Villacís Venegas, N., Moyano Cascante, M. V., \& Toledo Castillo, N. del R. (2019). La normativa legal como pilar de gestión en la economía social y solidaria del Ecuador. Ciencia Digital, 3(2.6), 238-251. https://doi.org/10.33262/cienciadigital.v3i2.6.561

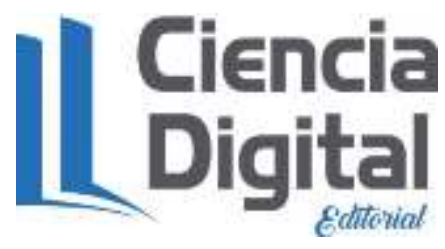

El artículo que se publica es de exclusiva responsabilidad de los autores y no necesariamente reflejan el pensamiento de la Revista Ciencia Digital.

El artículo queda en propiedad de la revista y, por tanto, su publicación parcial y/o total en otro medio tiene que ser autorizado por el director de la Revista Ciencia Digital.
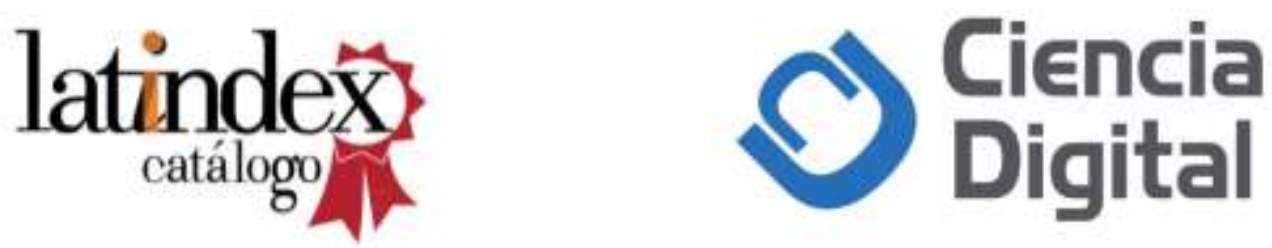